\title{
Primary and Secondary Prevention of Child Sexual Abuse
}

Natasha Knack, BA(Hons) ${ }^{1}$; Belinda Winder, $\mathrm{PhD}^{2}$; Lisa Murphy, $\mathrm{MA}^{3}$; John Paul Fedoroff, $\mathrm{MD}^{3,4}$

${ }^{1}$ Forensic Research Unit, Institute of Mental Health Research, The Royal, Ottawa, Ontario, Canada

${ }^{2}$ Sexual Offences, Crime and Misconduct Research Unit, Department of Psychology, Nottingham Trent

University, Nottingham, England

${ }^{3}$ Sexual Behaviours Clinic, Integrated Forensics Program, The Royal, Ottawa, Ontario, Canada

${ }^{4}$ Department of Psychiatry, Faculty of Medicine, University of Ottawa, Ottawa, Ontario, Canada

Corresponding Author:

Natasha Knack ${ }^{1}$

1145 Carling Ave.

Office 5467

Ottawa, Ontario

K1Z 7K4

Phone: 613-722-6521 ext. 6236

Email: Natasha.Knack@theroyal.ca 


\section{Abstract}

The high prevalence rates and numerous consequences associated with child sexual abuse makes preventing these offences a societal priority. Prevention strategies have traditionally involved only tertiary interventions, implemented by the criminal justice system after an offence has occurred. More recently, some have argued for a public health approach to preventing child sexual abuse, which includes interventions at the primary and secondary levels. Secondary prevention aims to provide treatment and support to those at-risk of sexually offending before any involvement with the legal system. Increased demand for secondary prevention services and early results from current initiatives demonstrate that at-risk individuals are willing to seek treatment without external pressure from the legal system, and often report numerous treatment-related benefits. These findings support the need for wide-spread implementation of primary and secondary prevention initiatives. The safety of children requires that we, as a society, stop merely reacting to sexual offences, and instead begin implementing proactive evidence-based strategies that can prevent even initial incidents of child sexual abuse. This article explores some of the many benefits and barriers associated with primary and secondary prevention, as well as strategies for overcoming these barriers. Recommendations for the development and implementation of prevention initiatives are also included. 


\section{Introduction}

Child sexual abuse (CSA) is an ongoing international problem, with global prevalence rates estimated at $18 \%$ to $20 \%$ for girls and $8 \%$ for boys, based on two meta-analyses including over 9.9 million participants across six continents (Pereda et al., 2009; Stoltenborgh et al., 2011). A more recent report from the United Nations Children's Fund (2014) stated that approximately 120 million girls worldwide have been sexually victimized at some point in their life; while boys are also at risk (although less so than girls), a global estimate was unavailable. A meta-analysis by Barth et al. (2013) found that the prevalence of CSA differed based on the severity of the sexual activity, however girls who experienced CSA were still found to have higher prevalence rates regardless of the whether the abuse was non-contact ( $31 \%$ vs. $17 \%$ ), contact ( $13 \%$ vs. $6 \%$ ), forced intercourse ( $9 \%$ vs. $3 \%)$, or mixed abuse (15\% vs. $8 \%$ ). Prevalence rates may also differ based on the age of the offender, with one study finding that among a sample of adolescents aged 15 to 17, both males and females in all age categories reported higher rates of sexual victimization by juvenile (i.e. under age 18) rather than adult perpetrators (Finkelhor et al., 2014).

High prevalence rates, along with the myriad of short and long-term consequences associated with CSA, make preventing these offences a societal priority. Personal consequences for the victim can include physical effects (e.g. injury, chronic pain, STIs, sexual dysfunction), mental illness (e.g. depression, PTSD, suicide attempts, substance abuse), emotional or interpersonal issues such as difficulty forming relationships, and more (DeGue et al., 2012; Felitti \& Anda, 2009; Harvey et al., 2007). There are also financial consequences, as it has been estimated that the annual cost of CSA (without attempting to account for the cost of harming a child) is USD\$124 billion in the United States (Fang et al., 2012), AUD\$3.9 billion in Australia (Taylor et al., 2008), and £3.2 billion in the United Kingdom (Saied-Tessier, 2014). To better protect children from harm, society needs to move toward more preventative approaches to CSA, as these have the ability to identify and address potential risk factors for offending before someone engages in illegal sexual behaviours, as opposed to the current reactionary strategies that require waiting until a child has been victimized. Effective prevention initiatives will not only reduce the number of children being sexually victimized, but they will also significantly reduce the costs associated with sexual offending.

One of the major challenges for organisations and individuals working in this area is that widespread public messages which draw attention to the prevalence and consequences of CSA also galvanise public fear and hatred toward those who may be at risk of perpetrating such abuse. The true purpose of these prevention initiatives may also be misunderstood by the media, general public, and policymakers, who may perceive them as attempts to protect potential or actual sex offenders, rather than protecting potential and actual victims (McCartan et al., 2018). This media-fuelled hostility, along with misunderstandings and misrepresentations of initiatives to prevent CSA, thwarts attempts to prevent people from engaging in sexual offences against children.

\section{Primary, Secondary, and Tertiary Prevention}

Child sexual abuse is a multifaceted problem associated with a range of motivating factors, and these offences are committed by a heterogeneous population. Consequently, it has been argued that effective prevention initiatives require the development and implementation of interventions at the primary, secondary, and tertiary levels. Adopted from the field of public health, these three levels of prevention have been described as follows: (1) Primary prevention involves wide-scale initiatives aimed at the general public and implemented 
before the occurrence of sexual violence to prevent even initial incidents of CSA (e.g. general crime deterrence, public education, adequate sex education in schools); (2) Secondary prevention involves more targeted interventions for those at-risk of engaging in CSA, which address issues known to increase the risk of offending (e.g. anonymous helplines for people with sexual interest in children); and (3) Tertiary prevention is a reactionary approach after a sexual offence has occurred, which aims to prevent sexual recidivism (e.g. treatment programs for those who have engaged in CSA) (Laws, 2000; Wortley \& Smallbone, 2006).

It has been argued that a lack of attention and resources have been dedicated to secondary prevention initiatives for CSA, focusing instead on primary and tertiary initiatives (McCartan et al., 2018). It is interesting that tertiary interventions aimed at addressing sexual recidivism have received the most attention, considering that reoffence rates for sexual offences are typically far lower than for most other offences. A meta-analysis by Hanson and Morton-Bourgon (2005) found the rate of sexual recidivism to be under $14 \%$ (this rate is at least somewhat inflated due to the inclusion of untreated offenders), which is significantly lower than recidivism rates (for any type of crime) found for property offenders (88\%), drug offenders (84\%), public order offenders (82\%), and violent offenders (79\%), after a nine-year follow-up period (Alper et al., 2018). While tertiary initiatives are clearly a necessary part of preventing sexual offending, attempting to implement initiatives at this level alone is not a sufficient response to a problem as complex and pervasive as CSA. Primary and secondary initiatives are even more relevant because up to $95 \%$ of sexual offences against children are committed by first-time offenders (Sandler et al., 2008). Research has also shown that men who have committed a sex offence may struggle with their sexual thoughts and urges for an average of five to ten years before committing the sexual offence (Knack et al., 2017; Piche et al., 2018), indicating that we, as a society, have time to prevent many of the sexual crimes that occur. While the current article focuses mainly on secondary prevention initiatives, the successful implementation of these initiatives is likely to also require interventions at the primary level in order to address the stigma and misunderstandings about pedophilia (Cooper, 2016; Jahnke \& Hoyer, 2013).

\section{Sexual Interest vs. Sexual Behaviour}

When designing strategies to prevent CSA, it is vital to recognize the difference between sexual interests and sexual behaviours. Adults with a persistent sexual interest in children, who have either acted on this interest or suffered distress from it, would meet the diagnostic criteria for Pedophilic Disorder (American Psychiatric Association, 2013). As with any other mental illness, people do not choose to have this disorder, and most people with pedophilia would greatly prefer to have non-criminal sexual desires and pro-social lives. In fact, many of these individuals "describe years of just agonizing self-hatred, agonizing fear of being detected as having a sexual interest in children, viewing themselves as monsters, being afraid to look for help" (Malone, 2014, pg. 29). While individuals are not at fault for their sexual interests, they are responsible for their sexual behaviours. It is important to emphasize that not all individuals who are diagnosed with Pedophilic Disorder have, or ever will, sexually abuse a child (Fedoroff, 2010). Pedophilic Disorder can be further classified as exclusive, non-exclusive, or incest-only type (American Psychiatric Association, 2013). The exclusive subgroup, which is thought to comprise only a very small percentage of all MAP, describes those with a more fixated and longstanding sexual interest in children that is often established during puberty (Tozdan \& Briken, 2015). In contrast to Pedophilic Disorder, child sexual abuse (both contact and non-contact) is a sexual behaviour committed by someone who may or may not have a sexual interest in children. Research has found that approximately $50 \%$ of men convicted of CSA do not meet the diagnostic criteria for pedophilia (Malamuth \& Huppin, 2007; Seto, 2008). 


\section{Motivations for Child Sexual Abuse}

People engage in CSA for a myriad of reasons, and understanding these distinct underlying motivations is a necessary part of designing specialized treatment interventions that can effectively prevent sexual offences against children (Marshall et al., 2006). Some individuals have proposed the term "minor-attracted people" (MAP) to describe individuals who are both sexually attracted to children and/or affectionate toward them. The fact that both minor-attracted people (MAP) and people without a sexual interest in children (non-MAP) engage in CSA indicates that the motivations underlying these behaviours are not clear-cut. Despite the common assumption that CSA is motivated solely by a person's sexual interest or their desire for sexual gratification, research has found that these offences are almost always associated with non-sexual motivations as well (Finkelhor, 1994; Hoberman, 2016). Designing effective prevention initiatives and treatment strategies for MAP and non-MAP requires a thorough understanding of which motivations are likely to be most pertinent to each group, as well as those that may overlap. For MAP, sexual attraction to children is likely an inherent part of the motivation to engage in CSA, yet research has indicated that other underlying motivators may also contribute to their offending behaviour, including abuse in childhood (Nunes et al., 2013; Sullivan \& Sheehan, 2016), cognitive distortions and abuse-supportive attitudes (Helmus et al., 2013), desire for intimacy and emotional gratification (Ward et al., 1993), and the use of maladaptive coping mechanisms that may indirectly lead to sexual offending (Ward et al., 2007). In some cases, MAP spend years successfully resisting their urge to engage in CSA (Piché et al., 2018), until the accumulation of multiple life stressors act as a catalyst for the transition from sexual interest to sexual behaviour (Leclerc et al., 2016). Studies have shown that a number of underlying motivations for engaging in CSA are endorsed by those both with and without a sexual interest in children. These include, but are not limited to, a lack of sexual knowledge, personal abuse during childhood, social skills and relationship difficulties, substance abuse or other mental health issues, and attempts to use children to satisfy their perceived emotional or sexual needs (Quinsey \& Lalumière, 1995; Sullivan \& Sheehan, 2016; Ward et al., 2007).

Explanations for why someone without a sexual interest in children may engage in CSA include a general anti-social orientation (Hanson \& Morton-Bourgon, 2005), a sexual interest in coercion (Turner-Moore \& Waterman, 2017), attitudes accepting of sex between adults and children (Cash, 2016), and indiscriminate or opportunistic sexual behaviours (Winder et al., 2018). Opportunistic offences may also result from an inability to establish relationships with age-appropriate adults, which may cause individuals to gravitate toward children, whom they consider to be less intimidating and judgmental (Sullivan, 2002; Ward et al., 2007). Studies have also indicated that feeling forced to repress one's pro-social sexual desires, typically in response to restrictive family, religious, or cultural regimes, may result in these desires manifesting as illegal sexual behaviours, including sexual contact with children (Sullivan \& Sheehan, 2016). Similarly, Knack et al. (2017) found that several men who had engaged in CSA described formative experiences involving the need to repress their healthy homosexual orientation due to restrictive regimes, which led them to engage in CSA because they perceived boys as being more easily accessible, less judgmental, and less likely to 'out' them. These findings in no way suggest that homosexuality is dangerous to children, but rather that repressing these perfectly healthy sexual desires can have serious and unexpected outcomes.

Individuals with intellectual and developmental disabilities are no more likely to commit sexual offences than those without these disabilities (Hocken, 2014), and are in fact more likely to be the victims of crime (National Autistic Society, 2016). However, some individuals with intellectual disabilities may seek sexual contact with a child because their opportunities for sexual expression are restricted by prohibitions of sexual behaviour placed on them by care providers. The counterfeit deviance hypothesis, first proposed by Hinsburger, Griffiths 
and Quinsey (1991), suggests that when people with intellectual disabilities engage in deviant sexual behaviour (e.g. sexual contact with children), it is important to determine whether these behaviours are an inappropriate expression of healthy sexual desires or evidence of an underling paraphilia. Failure to distinguish between these motivations can result in the use of inappropriate treatment interventions for this population. Similarly, while developmental disorders such as autism spectrum disorder (ASD) do not inherently predispose an individual to sexual offending, it is possible that features of these disorders may inadvertently contribute to offending behaviours (Murrie \& Warren, 2002), as those with an ASD who do offend often do so in the context of their autism (Allely \& Creaby-Attwood, 2016). Thus, preoccupation with (for example) the collecting of sexual images or even with sexuality itself, may become an antecedent to sexual offending. Research by Dillon, McNally, and Winder (2016) highlighted the need to accurately diagnose individuals convicted of a sexual offence, as understanding the role these disorders play in illegal sexual behaviours is an important part of designing treatment programs that are responsive to individuals' specific needs.

\section{Public Health Approach to Child Sexual Abuse}

According to the Moore Center for the Prevention of Child Sexual Abuse, "Child sexual abuse is a 100 percent preventable public health problem" (Letourneau, 2017, p. 1). A public health approach to CSA involves making relevant treatment and services widely available and encouraging those who may be at risk of offending to seek treatment before an offence has occurred (Brown et al., 2014). The World Health Organization (2002) has indicated that using a public health approach has the potential to reduce the rate of CSA. One of the key prevention strategies for both MAP and non-MAP involves offering community-based prevention programs that include pharmacological treatments intended to manage problematic sexual arousal. Support and services for individuals wishing to change their unwanted sexual thoughts, as well as treatment interventions that address the trauma experienced by individuals who have suffered abuse in their own childhoods, together with greater access to mental health services in general, are also needed.

To be successful, prevention initiatives not only need to make the public and at-risk individuals aware that effective treatment exists, they also need to ensure that these services are accessible. In addition to being widespread and affordable, accessibility also involves creating a social environment in which individuals with problematic sexual interests and individuals at-risk of offending, feel safe enough to seek help for this issue. Consequently, a successful public health approach also requires strategies for reducing the stigma of the term "pedophilia", and mental health treatment in general. It has been suggested that utilizing a widespread marketing campaign to begin changing the social and political climate toward this issue is a crucial first step to implementing improved public health initiatives against sexual offending (Piché et al., 2018). Tozdan and Briken (2015) have theorized that self-efficacy - an individual's belief that they are in control of their own behaviours and the events that shape their lives (Bandura, 1997) - may play a role in MAPs ability to change their sexual interest. In short, MAP who believe it is possible to change their sexual interest will likely be more motivated to do so, while those who are told they will never change are left with little motivation to even try. Self-efficacy may be especially relevant for secondary prevention initiatives, which aim to motivate MAP to seek treatment before any involvement with the legal system. As such, it is important that public education campaigns remain cognizant of the messages they send, in order to avoid further perpetuating myths and stereotypes about pedophilia or spreading information that is not empirically founded, and which may actually reduce MAPs motivation to seek treatment (or seek support for mental health issues related to the stigmatizing identity of being a MAP). 
Two of the most well-known secondary prevention initiatives include Stop it Now!, which originated in the United States in 1992 and has since expanded to include affiliate sites in the UK \& Ireland, Wales, the Netherlands, and Scotland (Brown et al., 2014; Eisenberg, Mulder, van Horn \& Stam, 2014), and the Prevention Project Dunkelfeld (PPD), a Berlin-based research project that started in 2005 and has developed into what is now known as the Prevention Network, with 12 treatment providers located across Germany (Beier et al., 2009a; Beier et al., 2009b). Both initiatives provide confidential support to those concerned about their sexual interests or behaviours; they also provide information to the general public regarding their role in helping prevent CSA. It should be noted that multiple German institutions, such as the Institute for Sexual Research and Forensic Psychiatry Hamburg, have provided therapeutic services for MAP who are not involved with the legal system since the 1960s (Briken, 2018). A complete listing of all secondary prevention initiatives worldwide is outside the scope of this article. However, as the current authors are presently leading two separate prevention projects, these initiatives are described in detail below.

Sexual Behaviours Clinic Prevention Study. Established in Ottawa (Canada) in 1983, The Royal's Sexual Behaviours Clinic (SBC) has provided assessment and treatment to over 4,000 people at all stages of the legal system, including those who have never offended. The SBC's Prevention Study aims to increase awareness of preventative treatments and encourage at-risk individuals to ask for help before offending. Rather than a helpline, which requires significant resources, the study uses a website (www.sexualbehavioursclinic.ca) to provide information and recruit participants. The website provides the unique ability for individuals to contact the research team completely anonymously, using the website's integrated messaging system, as opposed to a personal phone or email. Study participants complete questionnaires about their mental health, coping mechanisms, sexual interests/behaviours, etc. at baseline and six months post-baseline. At their baseline appointment, each participant is given the voluntary option of receiving treatment in the SBC. Through innovative intake and programming methods, the SBC maintains no wait list and participants are typically able to begin receiving specialized psychiatric treatment within one week of their initial research appointment. To date, every person who has entered the study has voluntarily gone on to accept treatment in the SBC. The SBC makes no distinction between those with 'exclusive' and 'non-exclusive' pedophilia, since treatment is focused on both decreasing sexual interest in children and increasing sexual interest in adults.

It has recently been reported that in Canada the only available interventions to prevent sexual offences by men with problematic sexual interests are at the tertiary level and administered by the criminal justice system, meaning that "the only way for individuals to access services for their sexual concerns is to actually commit a sexual offense" (Piche et al., 2018, p. 65). The SBC program and Prevention Study are evidence that this is no longer the case, yet due to a lack of available resources, the reach of the study is currently restricted primarily to Eastern Ontario. Interestingly, the research team has received requests for treatment from individuals in other Canadian provinces, as well as multiple places in the United States and as far as India, indicating an international need for this type of prevention program. Ideally, preliminary evidence from this study can be used to support more widespread implementation of secondary prevention initiatives in Canada. However, a nationwide response to CSA is unfeasible without government funding and support. Unlike in Germany and the UK, where prevention initiatives are well-supported by government and legal sectors (e.g. PPD receives annual ministry funding of $€ 5$ million; Scholz, 2016), political will to support preventative approaches in Canada is comparatively lacking (Piche et al., 2018). 
The Safer Living Foundation Prevention Project. The Safer Living Foundation (SLF) is a registered charity, established in 2014 as a joint venture between Whatton prison, Nottingham Trent University, the National Probation Trust (Nottinghamshire), and Nottinghamshire Police. Its charitable objectives are: (1) To promote the protection of people from, and the prevention of, sexual crime; and (2) To promote the rehabilitation of persons who have committed, or who are likely to commit, offences, particularly sexual offences against others. The charity recognises that people can be prevented from committing a sexual offence if the right help is offered at the right time. In response to this, the SLF set up a project (The Aurora Project) that provides a free treatment service for individuals who are concerned that they may sexually offend. The service was set up with input from a long-running service user group at Whatton prison run by Professor Belinda Winder, in which she meets with a group of six to eight current prisoners each month. This helps the charity to offer a prevention service that is fit for purpose as it utilises both the current evidence base together with the "lived experience" of people who have committed sexual offences.

The project runs in a specialist treatment centre in Nottingham city centre (though the service is open to people from any area who are willing to travel). The centre is managed by a multi-disciplinary team of treatment facilitators, psychologists and psychiatrists - all of whom are experienced in working with people who have committed sexual offences. The project offers a group-based intervention using third wave CBT methods, such as Acceptance and Commitment Therapy (ACT) and Compassion Focused Therapy (CFT). It addresses the dynamic risk and protective factors associated with sexual offending and helps participants flourish and thrive; for some that will involve having to accept and live with their sexual interests. The service also offers both individual support, as required, and/or medication to manage sexual arousal for those clients who are sexually preoccupied. Evaluation has been built into the service plan to monitor and assess the intervention.

\section{Demand for prevention services}

The expansion of the Stop it Now! and Prevention Project Dunkelfeld (PPD) programs, the ongoing emergence of new prevention initiatives for CSA, and the volume at which these programs are being used are all indicative of increased demand for preventative services that address CSA. From 2002 to 2017, the Stop it Now! UK \& Ireland Helpline received upwards of 60,000 calls, over $40 \%$ of which were made by MAP, and from 2013 to 2014 the demand was so high that an average of 2,199 calls went unanswered each month (Brown et al., 2014). Within the first 15 months of operation, the Stop it Now! Netherlands helpline was contacted by 254 individuals (Eisenberg et al., 2014). In 2016, the Stop it Now! Scotland website was accessed by 1,530 people, and the helpline received over 100 calls (Paedophile self-help site, 2018). Of the 476 individuals who contacted PPD within the first 18 months, 43\% elected to be assessed for treatment (Beier et al., 2009a). Piché et al. (2018) found that $91 \%$ of their sample of convicted sex offenders said they would consider using a preventative service in the future if needed, and $61 \%$ said they would have previously used a preventative service had it been available or known to them. The latter statement was more likely to be endorsed by participants who

reported greater concerns about their problematic sexual interests. A recent media campaign launched by the Lucy Faithfull Foundation, a UK-based charity devoted to preventing CSA, targeting users of online child sexual abuse images received approximately two million hits over eight months from people concerned about their behaviours (Sheath, 2016). Police in the UK have been supportive of secondary prevention initiatives that aim to address these behaviours before involvement with the criminal justice system. These initiatives may be a crucial part of addressing the problem of online sexual offending, as the sheer volume of online child sexual abuse images, and the difficulty in apprehending all these perpetrators, means that "We are not going to be able to arrest our way out of it" (Evans, 2014). 


\section{Benefits of Primary and Secondary Prevention}

Primary and secondary prevention of CSA has at least four potentially far-reaching benefits: (1) Preventing children from becoming victims of sexual abuse; (2) Helping people who may be at risk of offending get appropriate treatment to improve their quality of life and allow them to continue being pro-social members of society; (3) Saving the criminal justice time and resources by preventing both initial and subsequent incidents of CSA, thus moderating the number of offenders who need to be prosecuted and incarcerated for these offences; and (4) Reducing the strain on the health care system by avoiding the many possible physical and mental health consequences of experiencing sexual abuse. One of the critical functions of prevention initiatives is strengthening the protective factors that research has previously identified as significant to reducing the risk of CSA (Hanson \& Harris, 2001; Hanson \& Morton-Bourgon, 2005). Social support has been consistently identified as a protective factor, but unfortunately both potential and actual sexual offenders often experience intense feelings of alienation and social isolation due to the need to keep their sexual interests and behaviours hidden from family, friends, and even healthcare providers (Malone, 2014). Consequently, professionals working with these individuals have found that their "stories just poured out of them once a safe space for disclosure was provided", and that simply having someone to whom they could disclose their sexual interest was reported as having a preventative function for some individuals (McCartan et al., 2018, p. 14). Callers to the Stop it Now! Helpline reported improved emotional, psychological, and physical health, with one study finding that $76 \%$ of participants felt more in control of their behaviours, emotions, and situations, and $75 \%$ describing reductions in their feelings of social isolation (Brown et al., 2014). There was also strong support (86\%) for the belief that using the Stop it Now! helpline can help protect children that may be at risk of sexual abuse. Improved emotional functioning, fewer cognitive distortions, greater understanding and control of their own sexual interests, behaviours, and risk factors, as well as the development of new coping mechanisms to prevent future offending have also been reported (Beier et al., 2009; Beier et al., 2015; Brown et al., 2014; Eisenberg et al., 2014). Based on evidence that personal well-being and improved quality of life can result in desistance and improved ability to self-manage behaviours (Brown et al., 2014), findings from these and other initiatives support more widescale implementation of confidential support and treatment avenues for those at-risk of sexual offending.

The many possible consequences of experiencing sexual abuse indicates that those who have been victimized are more likely to incur higher health care costs and further strain the existing healthcare systems (ChildHelpInfoCenter, 2009; Nyamwathi \& Rjasnjanskaja, 2014). In contrast, the long-term effects of prevention initiatives include minimizing or eliminating many of the personal, social, and financial costs associated with the potential negative repercussions of experiencing CSA (Finkelhor, 2009; Letourneau et al., 2018). Consequently, the costs associated with developing and implementing prevention initiatives must be understood in relation to the many potential savings resulting from the prevention of CSA and its associated legal and medical costs (Aos et al., 2001), as well as the "significant savings in human suffering and pain" (Piche et al., 2018, p. 78).

\section{Economic benefits of prevention}

According to the National Society for the Prevention of Cruelty to Children (NSPCC), a conservative estimate of the cost of CSA in the United Kingdom is $€ 3.2$ billion per year. This includes expenses related to healthcare ( $€ 182$ million), the criminal justice system ( $£ 149$ million), and child services ( $£ 124$ million), as well as costs associated with lost productivity in the labor market due to the lasting impact of CSA (estimated at 2.7 billion) 
(Saied-Tessier, 2014). In the United States, recent estimates are even higher, with one study reporting that costs associated with CSA were over \$9 billion in 2015 alone (Letourneau, Brown, Fang, Hassan, \& Mercy, 2018). Cost-benefit analyses of tertiary services for those convicted of sexual offences consistently indicate that treating these individuals leads to significantly more savings than expenses (Aos et al., 2001; Marshall, Eccles, \& Barbaree, 1993). Although research is still limited, early results support the hypothesis that cost-benefit analyses of primary and secondary prevention initiatives would result in similar outcomes. Bowles (2014) conducted an economic analysis of the Stop it Now! UK \& Ireland Helpline, excluding the cost of harm to victims since estimating these costs was not feasible. The author assumed that: (1) The number of new callers per year would be on the lower end ( $n=452)$; (2) Offenders or potential offenders who contacted the Helpline would commit one less offence per year; and (3) This 'one less offence' would belong in the least severe offence category (with a cost of $\$ 1,811$ per offence). Based on these assumptions, the author estimated that savings to taxpayers would be approximately $\$ 818,400$ per year. Considering that the budget for the UK \& Ireland Helpline was $\$ 642,800$ in 2011-2012 this results in savings of $\$ 175,600$ for a single year (Bowles, 2014). It is important to note that this analysis used the lowest estimates for the number of callers, offences, and severity of offences, meaning that actual savings may be even higher.

Based on an average cost of $£ 65,000$ to incarcerate one person in the UK (including police, court fees, etc.), another UK-based prevention initiative has estimated that it would cost the government close to $£ 126$ million if all 1,936 of their expected clients in 2018 were sentenced to a period of imprisonment (StopSO, 2018). In contrast, they estimate that to treat all expected clients they would require $£ 735,000$ per year of government funding - $£ 200,000$ for staffing and administration, plus $£ 535,000$ to subsidize costs for the $20 \%$ of clients who cannot afford treatment. Based on this, the cost of providing these preventative services for one year is only £380 per client, meaning that for every client who does not offend in 2018 , the government would save a minimum of $£ 64,620$, and only 11 clients would need to avoid involvement with the criminal justice system in order to make the program entirely cost effective (StopSO, 2018). The full economic benefits of a prevention approach are incalculable, as there is no way to accurately determine the cost of the harm and suffering experienced by victims of CSA. As such, there should be no question that the potential benefits to children, their families, MAP, and society as a whole outweigh the cost of attempting to create prevention initiatives. Going forward, governments should more carefully consider these cost-benefit ratios when deciding whether to devote resources toward tertiary interventions (i.e. incarceration) versus primary and secondary prevention initiatives. This is especially important considering that the success of primary and secondary initiatives is likely dependent on the provision of government funding and support (Letourneau et al., 2018; Williams \& Donnelly, 2014).

\section{Barriers to Primary and Secondary Prevention}

Several practical, ethical, and systemic barriers, identified by both professionals and service users, have hindered the availability and accessibility of primary and secondary prevention initiatives intended to reduce CSA. While it is often assumed that MAP and those at-risk of sexual offending require external motivation to enter treatment (i.e. from the legal system), it has been found that when aware of available treatment options, many of these individuals seek treatment voluntarily and report finding it helpful (Beier et al., 2009). Thus, it is possible that a lack of knowledge about available treatments may be a larger barrier to accessing these services than a lack of personal motivation for treatment. Unfortunately, the guilt and shame associated with having a sexual interest in children, as well as the stigma associated with pedophilia, can prevent even those who are motivated for treatment from voluntarily seeking help for this issue. A survey of self-identified MAP found that 
$40 \%$ of participants wanted treatment for their sexual interest but did not seek it out due to fears that they would be misunderstood (85\%), treated with disrespect (54\%), or that the treatment provider would be judgmental (63\%), unethical (46\%) or not respect confidentiality (51\%) (Testa \& West, 2010). Research has also found that individuals were deterred from seeking treatment for their problematic sexual interests as they were unaware of how to identify or access relevant services prior to involvement with the criminal justice system, or simply assumed that no such services existed (Chasan-Taber \& Tabachnic, 1999; Van Horn et al., 2015). McCartan et al. (2018) reported that some individuals were hesitant to search for available services online or disclose their sexual issues to a healthcare provider in order to get a treatment referral, as they were uncertain of the legal consequences of these actions. These findings are in line with another recent study, which found that barriers to treatment included participants' concerns they would be arrested or labeled as a sexual deviant, as well as concerns about privacy and anonymity (Piché et al., 2018). These concerns may be especially prominent for individuals who are sexually attracted to children but have not acted on this sexual interest.

Based on outcomes from their prevention pilot project, Van Horn et al. (2015) identified a number of internal and external barriers to the successful prevention of CSA. Internal barriers included denial and minimization of sexual problems, refusal to acknowledge the harmful effects of illegal sexual behaviours, fears concerning disclosure, and shame and guilt related to their sexual interests and/or behaviours. Even individuals who have never engaged in any illegal sexual behaviours often experience extreme feelings of shame and guilt regarding their problematic sexual interests (Malone, 2014). These feelings can often fuel individuals' fears that their sexual interests or behaviours will be identified, and the possibility of being 'outed' as having a sexual interest in children can in turn lead to isolation and a lack of social supports. These fears are not unjustified. Two studies on public stigma towards pedophilia found that between $14 \%$ and $28 \%$ of participants felt it would be better if people with pedophilia were dead, even if they'd never offended (Jahnke, Imhoff, \& Hoyer, 2015). This may explain why Piche et al. (2018) found that only a small percentage of participants had ever sought treatment for their sexual issues (18\%) or spoken to friends or family members about these issues (18\%). Reasons provided by participants included feeling too ashamed (55\%), not knowing whom to tell (51\%), being too shy (43\%), and feeling that it was not important to discuss their sexual issues (24\%).

External barriers identified by Van Horn et al. (2015) included a lack of knowledge about existing treatment options and referral sources, as well as the limited availability of applicable resources. These barriers may relate to a lack of awareness or reluctance among health and legal professionals to inform individuals about prevention initiatives, as well as a lack of clinicians qualified to treat problematic sexual interests. McCartan et al. (2018) note that one explanation for professionals' unease with the use of secondary prevention initiatives for CSA may relate to the ethical 'gray area' regarding the degree to which it is a healthcare provider's duty to probe someone who is not already involved with the legal system for information about potential offending behaviours. In some cases, even if clinicians are available, the cost of private counselling sessions can make this option unfeasible for some (Piche et al., 2018). In Canada, for example, psychiatric treatment is covered by the Ontario Health Insurance Plan (OHIP), but psychological treatment requires paying out of pocket for those who do not have personal health insurance (and even then, the coverage is limited).

\section{Overcoming Barriers and Future Directions}

Much of the current research on prevention initiatives for CSA indicates that reducing the stigma toward MAP, especially those who have never acted on this sexual interest, is an essential step toward eradicating the barriers that deter at-risk individuals from seeking help (Jahnke \& Hoyer, 2013). Consequently, widespread 
education on problematic sexual interests and behaviours is needed, both for professionals working in the health and criminal justice fields, as well as the general public. The media's role in this endeavour cannot be overlooked, as any attempt to alter the social landscape will require a significant change in the way that pedophilia is portrayed to the public in news stories, television, movies, etc. For example, rather than reacting to the word pedophile with questions akin to, 'but what if it was my child who was sexually abused?', perhaps people should also be asking themselves, 'what if it was my child who had pedophilia?'. Pedophilic Disorder is a psychiatric illness which, like other mental health issues, affects people through no fault of their own. If someone's own child was the one suffering from pedophilia, experiencing extreme feelings of shame and selfloathing because of their sexual thoughts, possibly even suicidal or at-risk of acting on this sexual interest wouldn't they want them to be able to seek treatment for this illness in order to live a happy, healthy, prosocial life?

Based on the limited amount of current scientific knowledge, we agree with Tozdan et al. (2018) that clinicians and researchers should avoid "generalized and absolute statements about the immutability of a sexual interest in children" (p. 10), not only to their clients, but also to other professionals and the media. Proclamations of this nature are likely to do more harm than good, as they may reduce the self-efficacy of MAP to change their sexual interests, while simultaneously increasing public stigma toward these individuals. However, treatment providers should be cognizant that if MAP exist on a spectrum with regard to the exclusivity of their sexual interest in children, it may be inappropriate to assume that the small minority of MAP who are exclusively interested in children are equally amenable to treatment (Tozdan \& Briken, 2015). As such, treatment interventions may need to be adjusted accordingly. Participants in a US-based prevention project indicated that hearing from others who had been successfully treated and were now living healthy and productive lives in the community would have the largest impact on their decision to access this service (Chasan-Taber \& Tabachnic, 1999). This finding may be related to hope theory, and the idea that hope can act as a protective mechanism against offending behaviours (Moulden \& Marshall, 2005). Unfortunately, the stigma associated with having a sexual interest in children prevents those who have been successfully treated from speaking out about their experiences.

Regarding the ethical 'grey area' that may deter some healthcare providers from offering or recommending these types of interventions, possible strategies that have been suggested for mitigating these ethical barriers include providing comprehensive and explicit explanations to both treatment providers and service users regarding what information would be asked, whether the sessions would be recorded, and what information falls under local mandatory reporting laws (McCartan et al., 2018). Finding an appropriate balance between protecting public safety and maintaining the therapeutic relationship is crucial to the success of secondary prevention initiatives, as it has been found that individuals are less likely to seek help if it would involve having their identity or other information about themselves revealed to the criminal justice system (Beier et al., 2009a; Brown et al., 2014). In the SBC, patients are informed of the mandatory reporting laws and the fact that the SBC abides by these laws, as this allows children to be protected from harm. In this way, patients are helped to understand that their successful treatment is a benefit both to themselves and others.

\section{Recommendations for program development and implementation}

The design of effective primary and secondary prevention initiatives depends on many factors, including (but not limited to) the specific goals of the program and targeted populations, available funding and resources, program location (including local mandatory reporting requirements), and service delivery methods. For example, helplines may be considered an ideal method for service delivery, yet they require significant 
resources that may not be available to those with limited funding. Decisions regarding program development and implementation should be thoroughly informed and evidence-based whenever possible, as these decisions will likely determine the success or failure of these initiatives. Treatment interventions should be tailored to address clients' individual needs, and the use of 'one size fits all' treatment strategies should be avoided. Programs should provide a range of possible treatment options (all of which should be completely voluntary), such as psychotherapy, assistance finding housing or employment, and medications to reduce sexual arousal (e.g. anti-androgen medications) or treat other psychiatric illnesses such as mood and anxiety disorders. Ideally, prevention programs will employ a multi-disciplinary staff equipped to meet the diverse needs of their clientele, including at least one psychiatrist who has the necessary training to administer and monitor medications, as well as diagnose Pedophilic Disorder. If programs are unable to employ a multi-disciplinary staff, collaborations between multiple community organizations are encouraged as a means of providing clients access to essential resources. Having a psychiatrist on staff is also advantageous as some specialized services (e.g. substance abuse programs, mood disorders clinics) may require a physician's referral. Program development will also require decisions regarding clinical practices, including whether treatment interventions will differ for individuals considered to have an exclusive versus non-exclusive sexual interest in children (Tozdan \& Briken, 2015). It is recommended that these decisions be made in consultation with psychiatric professionals.

Important decisions will also need to be made with regard to promotional strategies. Successful advertising campaigns are crucial to the success of prevention initiatives, as even a well-developed program cannot be effective if its existence is unknown. Results from Prevention Project Dunkelfeld (PPD) indicate that the following criteria were necessary when developing a campaign to recruit MAP into treatment: (1) Showing empathy and understanding of their difficult situation; (2) Avoiding discrimination based on an individual's sexual preference(s); (3) Reducing fear of legal repercussions; (4) Ensuring confidentiality and anonymity; and (5) Decreasing feelings of guilt and shame (Beier et al., 2009a). Callers to the Stop it Now! helpline identified similar factors as being most relevant to their decision to contact the helpline (Brown et al., 2014). Piche et al. (2018) found that the resources considered most important by sexual offenders themselves included free counselling (81\%), free group treatment (48\%), the existence of a helpline (48\%), free online counselling (34\%), and self-help books (18\%). Decisions about advertising strategies may need to account for differences based on program location. Brown et al. (2014) found the most effective methods of promoting the Stop it Now! UK \& Ireland helpline were through the police force (33.7\%) and websites (19\%), with less than $1 \%$ hearing about the helpline from the media. In contrast, the majority of people who contacted the Stop it Now! Netherlands helpline reported learning about it from TV, radio, or print media (NatCen Social Research, 2014). Schaefer et al. (2010) studied 160 people who had contacted PPD and found the majority had also become aware of the study through these same media sources $(41 \%)$, however in this case the remainder of referrals came primarily from medical and social welfare professionals (24\%) and the Internet (15\%).

Following media campaigns or news coverage of the Stop it Now! Netherlands helpline, the number of calls to the helpline increased to almost double the usual average of three calls per day (Van Horn et al., 2015). This indicates that effective prevention initiatives will likely require significant media engagement and close attention to public relations, specifically regarding the messages being portrayed and how these will be perceived by the public, healthcare and legal professionals, policy makers, and those who may be at-risk of engaging in CSA. It has been suggested that organizations and professionals working in the field of prevention should help to shape these public messages through proactive engagement with the media and the dissemination of important information, such as the distinction between pedophilia and sexual offending, and the many potential benefits of primary, secondary, and tertiary prevention initiatives (McCartan et al., 2018). 
As the success of prevention initiatives relies on many of the decisions made during the design phase, the Lucy Faithfull Foundation has created an extensive toolkit that can be used to navigate the complicated process of designing these interventions (https://ecsa.lucyfaithfull.org/).

\section{Conclusions}

It is not difficult to understand why the mention of child sexual abuse can incite such an immediate and intense emotional reaction. Yet for too long these emotional reactions have been allowed to dictate the way that we, as a society, address the issue of CSA. While understandable, these emotions rarely lead to effective solutions to the problem, but rather lead to acts of vigilantism or public outcry to 'lock 'em up and throw away the key' (Duell, 2018; Brown, 2013). Media-fuelled fears, along with oversimplified or incorrect characterizations of sexual offenders, can result in tertiary legal strategies (e.g. residency restrictions, sex offender registries) that are not evidence-based, and which may actually increase the risk of sexual recidivism (Finkelhor, 2009). As terms like 'pedophile' and 'child molester' are used interchangeably in the media, the stigma, hatred, and disgust that is typically felt towards those who sexually abuse children becomes inherently associated with MAP, regardless of whether they've acted on their sexual interest. People do not ask to be sexually interested in children, the overwhelming majority would prefer not to have this sexual interest, and many spend years or even lifetimes resisting their sexual urges (Fedoroff, 2010; Piché et al., 2018). Misunderstandings of the law and fears about 'thought police' (i.e. being arrested solely for having sexual thoughts about children) can also prevent these individuals from seeking treatment before they offend. If society truly wants to move toward a world in which no children are sexually abused, it is time people begin to understand that their own emotional reactions, however justifiable they may be, cannot be permitted to hinder or override evidence-based strategies that can help ensure the safety and wellbeing of children, including those at the primary and secondary levels. The ability of primary and secondary prevention initiatives to circumvent even initial sexual offences is nothing short of life-changing, and there is no reason why individuals who are at-risk of engaging in CSA should have to wait until after they've offended to be given access to treatment.

Declaration of interest: The authors report no conflicts of interest. The Sexual Behaviours Clinic Prevention Study is funded by the University of Ottawa Medical Research Fund. The Safer Living Foundation Prevention Project is funded by the Henry Smith Charity and Nottinghamshire Police and Crime Commissioner. The authors alone are responsible for the content and writing of the paper. 


\section{References}

Allely, C., \& Creaby-Attwood, A. (2016). Sexual offending and autism spectrum disorders. Journal of Intellectual Disabilities and Offending Behaviour, 7(1), 35-51.

Alper, M., Durose, M.R., \& Markman, J. (2018). 2018 update on prisoner recidivism: A 9-year follow-up period (2005-2014). U.S. Department of Justice, Bureau of Justice Statistics. Retrieved from: https://www.bjs.gov/content/pub/pdf/18upr9yfup0514.pdf.

American Psychiatric Association. (2013). Diagnostic and statistical manual of mental disorders ( $5^{\text {th }}$ Ed.). Washington, DC.

Aos, S., Phipps, P., Barnoski, R., \& Lieb, R. (2001). The comparative costs and benefits of programs to reduce crime-Version 4. Olympia: Washington State Institute for Public Policy.

Bandura, A. (1997). Self-efficacy: The exercise of control. New York: Freeman.

Barth, J., Bermetz, L., Heim, E., Trelle, S., \& Tonia, T. (2013). The current prevalence of child sexual abuse worldwide: A systematic review and meta-analysis. International Journal of Public Health, 58, 469-483. doi:10.1007/s00038-012-0426-1.

Beier, K.M., Ahlers, C.J., Goecker, D., Neutze, J., Mundt, I.A., Hupp, E., \& Schaefer, A.G. (2009a). Can pedophiles be reached for primary prevention of child sexual abuse? First results of the Berlin Prevention Project Dunkelfeld (PPD). Journal of Forensic Psychiatry \& Psychology, 20, 851-867. doi:10.1080/14789940903174188.

Beier, K.M., Neutze, J., Mundt, I.A., Ahlers, C.J., Goecker, D., Konrad, A., \& Schaefer, G.A. (2009b). Encouraging self-identified pedophiles and hebephiles to seek professional help: First results of the Prevention Project Dunkelfeld (PPD). Child Abuse \& Neglect, 33, 545-549. doi:10.1016/j.chiabu.2009.04.002.

Bowles, R. (2014). Economic analysis of the Stop it Now! UK and Stop it Now! Netherlands Helplines: Summary Report. Retrieved from: http://www.natcen.ac.uk/media/338803/stop-it-now-economic-analysis.pdf.

Briken, P. (2018). Prävention sexuellen Kindesmissbrauchs im Dunkelfeld - das Hamburger Modell. Psychotherapie, Psychosomatik, Medizinische Psychologie, 68, 142-161. doi:10.1055/s-0043-121680.

Brown, P. (2013). “Castrate 'Em!". In K. Harrison \& B. Rain (Eds.), The Wiley-Blackwell Handbook of Legal and Ethical Aspects of Sex Offender Treatment and Management (pp. 129-149). doi:10.1002/9781118314876.ch8

Brown, A., Jago, N., Kerr, J., Nicholls, C.M., Paskell, C., \& Webster, S. (2014). Call to keep children safe from sexual abuse: A study use and effects of the Stop it Now! UK and Ireland Helpline. NatCen Social Research.

Cash, B.M. (2016). Self-Identifications, Sexual Development, and Wellbeing in Minor-Attracted People: 
An Exploratory Study. Unpublished thesis, Cornell University, New York.

Chasan-Taber, L., \& Tabachnick, J. (1999). Evaluation of a Child Sexual Abuse Prevention Program. Sexual Abuse: A Journal of Research and Treatment, 11, 279-292. doi:10.1177/107906329901100404.

ChildHelpInfoCenter. (2009). Arizona Child Abuse Info Center: Critical information for ensuring the protection of children and youth. Retrieved from:

http://childhelpinfocenter.org/index.php?option=com_content\&task=view\&id=29\&Itemid=42.

Cooper, J. (2010). Educating all adults will help to prevent child sex abuse. Community Care, 1827, 18.

DeGue, S., Holt, M.K., Massetti, G.M., Matjasko, J.L., Tharp, A.T., \& Valle, L.A. (2012). Looking ahead toward community-level strategies to prevent sexual violence. Journal of Women's Health, 21, 1-3. doi:10.1089/jwh.2011.3263.

Dillon, G., McNally, T., \& Winder, B. (2016). An exploration of the relationship between the collecting behaviours of internet sex offenders and Autism Spectrum Disorder: Implications for sentencing and treatment needs. IATSO Conference.

Duell, M. (2018, August). Outrage as vigilante paedophile hunters 'dressed like police' handcuff a suspect in footage streamed live on Facebook. Daily Mail. Retrieved from:

http://www.dailymail.co.uk/news/article-6094351/Outrage-vigilante-paedophile-hunters-dressed-likepolice.html.

Eisenberg, M., Mulder, J., van Horn, J., \& Stam, J. (2014). Stop it Now! Helpline Netherlands: A study of its use and effects - English summary. Retrieved from: http://www.natcen.ac.uk/media/338804/stop-it-nownl-findings.pdf.

Evans, M. (2014). Thousands of paedophiles will escape justice, crime chief admits. The Telegraph. Retrieved from: http://www.telegraph.co.uk/news/uknews/crime/11174715/ Thousands-of paedophiles-willescape-justice-crime-chiefadmits.html.

Fang, X., Brown, D.S., Florence, C.S., \& Mercy, J.A. (2012). The economic burden of child maltreatment in the United States and implications for prevention. Child Abuse and Neglect, 36, 156-165. doi:10.1016/j.chiabu.2011.10.006.

Fedoroff, J.P. (2010). Paraphilic Worlds. In C.B. Risen, S.E. Althof, \& S.B. Levine (Eds.), Handbook of Clinical Sexuality for Mental Health Professionals $2^{\text {nd }}$ Ed. (pp. 401-424). New York, NY: Routledge/Taylor \& Francis Group.

Felitti, V., \& Anda, R. (2009). The relationship of adverse childhood experiences to adult medical disease, psychiatric disorders, and sexual behavior: Implications for healthcare. In R. Lanius \& E. Vermetten (Eds.), The Hidden Epidemic: The Impact of Early Life Trauma on Health and Disease (pp. 77-86). Cambridge, UK: Cambridge University Press.

Finkelhor, D. (1994). Current information on the scope and nature of child sexual abuse. The Future of Children, 4, 31-53. 
Finkelhor, D. (2009). The prevention of childhood sexual abuse. The Future of Children, 19, 169-194.

Finkelhor, D., Shattuck, A., Turner, H.A., \& Hamby, S.L. (2014). The lifetime prevalence of child sexual abuse and sexual assault assessed in late adolescence. Journal of Adolescent Health, 55, 329-333. doi:10.1016/j.jadohealth.2013.12.026.

Hanson, R.K. \& Harris, A.J.R. (2001). A structured approach to evaluating change among sexual offenders. Sexual Abuse: A Journal of Research and Treatment, 13, 105-122. doi:10.1023/A:1026600304489.

Hanson, R.K. \& Morton-Bourgon, K. E. (2005). The characteristics of persistent sexual offenders: A metaanalysis of recidivism studies. Journal of Consulting and Clinical Psychology, 73, 1154-1163. doi:10.1037/0022-006X.73.6.1154.

Harvey, A., Garcia-Morena, C., \& Butchart, A. (2007, May 2-3). Primary prevention of intimate-partner violence and sexual violence. Background paper for World Health Organization expert meeting, Geneva, Switzerland. Retrieved from: http://www.who.int/violence_injury_prevention/publications/violence/IPV-SV.pdf.

Helmus, L., Hanson, R.K., Babchishin, K.M., \& Mann, R.E. (2013). Attitudes supportive of sexual offending predict recidivism: A meta-analysis. Trauma, Violence, and Abuse, 14, 34-53. doi:10.1177/1524838012462244.

Hingsburger, D., Griffiths, D., \& Quinsey, V. (1991). Detecting counterfeit deviance: Differentiating sexual deviance from sexual inappropriateness. Habilitation Mental Health Care Newsletter, 10, 51-54.

Hoberman, H.M. (2016). Personality and sexual offending: Non-sexual motivators and disinhibition in context. In A. Phenix \& H. Hoberman (Eds.), Sexual Offending (pp. 119-184). New York, NY: Springer.

Hocken, K. (2014). How effectively does the Structured Assessment for Risk and Need for Sexual Offenders (SARNSO) assess risk in intellectually disabled sexual offenders? Unpublished PhD thesis: Nottingham Trent University, Nottingham, UK.

Jahnke, S. \& Hoyer, J. (2013). Stigmatization of people with pedophilia: A blind spot in stigma research. International Journal of Sexual Health, 25, 169-184. doi:10.1080/19317611.2013.795921.

Jahnke, S., Imhoff, R., \& Hoyer, J. (2015). Stigmatization of people with pedophilia: Two comparative surveys. Archives of Sexual Behavior, 44, 21-34. doi:10.1007/s10508-014-0312-4.

Knack, N., Holmes, D., Trunzo, M., \& Fedoroff, P. (2017, February). Motivations to offend: Hands-on vs. handsoff sex offenders. Paper presented at the $69^{\text {th }}$ annual meeting of the American Academy of Forensic Sciences, New Orleans, LA.

Laws, D. R. (2000). Sexual offending as a public health problem: A North American perspective. Journal of Sexual Aggression, 5, 30-44. doi:10.1080/13552600008413294. 
Leclerc, B., Wortley, R., \& Dowling, C. (2016). Situational precipitators and interactive forces in sexual crime events involving adult offenders. Criminal Justice and Behavior, 43, 1600-1618. doi:10.1177/0093854816660144.

Letourneau, E. (2017, September 14). Watch my TEDMED talk on child sexual abuse prevention: Prevention is the only way to end victimization. Psychology Today. Retrieved from: https://www.psychologytoday.com/intl/blog/prevention-now/201709/watch-my-tedmed-talk-childsexual-abuse-prevention.

Letourneau, E. J., Brown, D. S., Fang, X., Hassan, A., \& Mercy, J. A. (2018). The economic burden of child sexual abuse in the United States. Child Abuse and Neglect, 79, 413-422. doi:10.1016/j.chiabu.2018.02.020

Malamuth, N. \& Huppin, M. (2007). Drawing the line on virtual child pornography: Bringing the law in line with the research evidence. N.Y.U Review of Law and Social Change, 31, 773-789.

Malone, L. (2014). You're 16. You're a pedophile. You don't want to hurt anyone. What do you do now? Retrieved from: https://medium.com/matter/youre-16-youre-a-pedophile-you-dont-want-to-hurtanyone-what-do-you-do-now-e11ce4b88bdb.

Marshall, W.L., Eccles, A., \& Barbaree, H.E. (1993). A three-tiered approach to the rehabilitation of incarcerated sex offenders. Behavioral Sciences \& the Law, 11, 441-455. doi:10.1002/bsl.2370110410.

Marshall, W. L. \& Marshall, L. E. (2000). The origins of sexual offending. Trauma, Violence, and Abuse, 1(3), 250263.

Marshall, W.L., Marshall, L.E., \& Serran, G.A. (2006). Strategies in the treatment of paraphilias: A critical review. Annual Review of Sex Research, 17, 162-182.

McCartan, K. F., Merdian, H. L., Perkins, D. E., \& Kettleborough, D. (2018). Ethics and issues of secondary prevention efforts in child sexual abuse. International Journal of Offender Therapy and Comparative Criminology, 62, 2548-2566. doi:10.1177/0306624X17723951.

Moulden, H.M. \& Marshall, W.L. (2005). Hope in the treatment of sexual offenders: The potential application of hope theory. Psychology, Crime, \& Law, 11, 329-342.

Murrie, C., \& Warren, I. (2002). Asperger's syndrome in forensic settings. International Journal of Forensic Mental Health, 1(1), 59-70.

NatCen Social Research. (2014). A public health approach to tackling child sexual abuse: Research on Stop it Now! UK and Ireland and Stop it Now! Netherlands. Retrieved from http://www.natcen.ac.uk/media/329130/overview-of-study complete-web.pdf.

Nunes, K.L., Hermann, C.A., Malcom, J.R., \& Lavoie, K. (2013). Childhood sexual victimization, pedophilic interest, and sexual recidivism. Child Abuse and Neglect, 37, 703-711.

Doi:10.1016/j.chiabu.2013.01.008. 
Nyamwathi, R. \& Rjasnjanskaja, T. (2014). Impact of child sexual abuse among the youth: Ways of caring for them. Turku University of Applied Sciences. Retrieved from:

https://www.theseus.fi/bitstream/handle/10024/106247/combined document.pdf?sequence=1.

Paedophile self-help site Stop It Now used 1,530 times. (2017, February 10). BBC News Scotland. Retrieved from: https://www.bbc.com/news/uk-scotland-38922239.

Pereda, N., Guilera, G., Forns, M., \& Gómez-Benito, J. (2009). The prevalence of child sexual abuse in community and student samples: A meta-analysis. Clinical Psychology Review, 29, 328-338. Doi:10.1016/j.cpr.2009.02.007.

Piché, L., Mathesius, J., Lussier, P., \& Schweighofer, A. (2018). Preventative services for sexual offenders. Sexual Abuse: A Journal of Research and Treatment, 30, 63-81. doi:10.1177/1079063216630749.

Quinsey, V.L. \& Lalumière, M.L. (1995). Evolutionary perspectives on sexual offending. Sexual Abuse: A Journal of Research and Treatment, 7, 301-315. doi:10.1007/BF02256834.

Saied-Tessier, A. (2014). Estimating the costs of child sexual abuse in the UK. NSPCC, 1-44. Retrieved from: https://www.nspcc.org.uk/globalassets/documents/research-reports/estimating-costs-child-sexualabuse-uk.pdf.

Sandler, J.C., Freeman, N.J., \& Socia, K.M. (2008). Does a watched pot boil? Time-series analysis of New York State's sex offender registration and notification law. Psychology, Public Policy and Law, 14, 284-302. doi:10.1037/a0013881.

Schaefer, G.A., Mundt, I.A., Feelgood, S., Hupp, E., Neutze, J., Ahlers, C.J., Goecker, D., \& Beier, K.M. (2010). Potential and Dunkelfeld offenders: Two neglected target groups for prevention of child sexual abuse. International Journal of Law and Psychiatry, 33, 154-163. doi:10.1016/j.ijlp.2010.03.005.

Scholz, K. (2016, October 25). Model project for paedophiles saved. Deutsche Welle. Retrieved from: http://p.dw.com/p/2RhOs.

Seto, M. (2008). Pedophilia and Sexual Offending Against Children: Theory, Assessment, and Intervention. Washington: APA.

Sheath, M. (2016, June). Secondary prevention and the Lucy Faithfull Foundation. Paper presented at the annual meeting of NSPCC Rebuilding Childhood, Edinburgh, UK.

Stoltenborgh, M., van IJzendoorn, M.H., Euser, E.M., \& Bakermans-Kranenburg, M.J. (2011). A global perspective on child sexual abuse: Meta-analysis of prevalence around the world. Child Maltreatment, 16, 79-101. doi:10.1177/1077559511403920.

StopSO. (2018, February 7). The government is putting children at risk of sexual abuse by failing to fund preventative therapy, says sexual abuse charity. StopSO Press Release. Retrieved from: http://www.stopso.org.uk/press-release/. 
Sullivan, J. (2002). The spiral of sexual abuse: A conceptual framework for understanding child sex offender behavior. NOTA News, 41, 17-21. Retrieved from: https://ncjtc-

static.fvtc.edu/Resources/RS00002865.pdf.

Sullivan, J. \& Sheehan, V. (2016). What motivates sexual abusers of children? A qualitative examination of the spiral of sexual abuse. Aggression and Violent Behavior, 30, 76-87. doi:10.1016/j.avb.2016.06.015.

Taylor, P., Moore, P., Pezzullo, L., Tucci, J., Goddard, C., \& De Bortoli, L. (2008). The cost of child abuse in Australia. Australian Childhood Foundation and Child Abuse Prevention Research Australia: Melbourne. Retrieved from: https://www.researchgate.net/publication/264546577_The_Cost_of_Child_Abuse_in_Australia.

Testa, M. \& West, S.G. (2010). Civil commitment in the United States. Psychiatry (Edgemont), 7, 30-40.

Tozdan, S. \& Briken, P. (2015). 'I believed I could, so I did' - A theoretical approach on self-efficacy beliefs to positively influence men with a risk to sexually abuse children. Aggression and Violent Behavior, 25, 104-112. doi:10.1016/j.avb.2015.07.015.

Tozdan, S., Kalt, A., Keller, L.B., \& Briken, P. (2018). Keep faith in yourself! A pilot study on the relevance of specific self-efficacy for modifying sexual interest in children among men with a risk to sexually abuse children. Journal of Sex \& Marital Therapy, 1-14. doi:10.1080/0092623X.2018.1437488.

Turner-Moore, T. \& Waterman, M. (2017). Men presenting with sexual thoughts of children or coercion: Flights of fancy or plans for crime? Journal of Sexual Medicine, 14, 113-124.

United Nations Children's Fund. (2014). Hidden in plain sight: A statistical analysis of violence against children. Retrieved from: https://www.unicef.org/publications/files/Hidden in plain sight statistical analysis Summary EN 2 Sept 2014.pdf.

Van Horn, J., Eisenberg, M., Nicholls, C.M., Mulder, J., Webster, S., Paskell, C., ... Jago, N. (2015). Stop it Now! A pilot study into the limits and benefits of a free helpline preventing child sexual abuse. Journal of Child Sexual Abuse, 24, 853-872. doi:10.1080/10538712.2015.1088914.

Ward, T., Hudson, S.M., \& France, K.G. (1993). Self-reported reasons for offending behavior in child molesters. Annals of Sex Research, 6, 139-148. doi:10.1007/BF00849304.

Ward, T., Mann, R.E., \& Gannon, T.A. (2007). The good lives model of offender rehabilitation: Clinical implications. Aggression and Violent Behavior, 12, 87-107. doi:10.1016/j.avb.2006.03.004.

Williams, D.J. \& Donnelly, P.D. (2014). Is violence a disease? Situating violence prevention in public health policy and practice. Public Health, 128, 960-967. doi:10.1016/j.puhe.2014.09.010.

Winder, B., Lievesley, R., Elliott, H., Hocken, K., Faulkner, J., Norman, C., \& Kaul, A. (2018). Evaluation of the use of pharmacological treatment with prisoners experiencing high levels of hypersexual disorder. The Journal of Forensic Psychiatry \& Psychology, 29(1), 53-71. 
World Health Organization. (2002). World report on violence and abuse [online]. Retrieved from: http://www.who.int/violence_injury_prevention/violence/world_report/en/full_en.pdf.

Wortley, R. \& Smallbone, S. (2006). Situational prevention of child sexual abuse. Monsey, NY: Criminal Justice Press. 